\title{
PROCESSO DE PINTURA EM PÓ: ANÁLISE DOS CUSTOS OCULTOS EM UMA INDÚSTRIA METALFAB
}

\section{POWDER PAINT PROCESS: ANALYSIS OF HIDDEN COSTS IN AN INDUSTRY METALFAB}

\author{
Loana Wollmann Taborda ${ }^{1}$; Lucinéia Carla Loeblein ${ }^{2}$; Andreas Dittmar Weise ${ }^{3}$; Sérgio Luiz Jahn ${ }^{4}$ \\ ${ }^{1}$ Universidade Federal de Santa Maria - UFSM \\ loanataborda@yahoo.com.br \\ ${ }^{2}$ Universidade Federal de Santa Maria - UFSM \\ lucineiacarla@yahoo.com.br \\ ${ }^{3}$ Universidade Federal de Santa Maria - UFSM \\ andreas.weise@ufsm.br \\ ${ }^{4}$ Universidade Federal de Santa Maria - UFSM \\ jahn@smail.ufsm.br
}

\begin{abstract}
Resumo
A necessidade de redução de custos nas empresas é uma prática obrigatória para a manutenção das mesmas no mercado atualmente tão competitivo. Neste trabalho são apresentados os resultados de uma pesquisa, realizada em uma indústria do ramo metal mecânico, que teve como objetivo analisar o custo adicional gerado pela aplicação de excesso de tinta em pó. O excedente da aplicação de tinta em pó em peças fabricadas em aço, além de causar problemas de qualidade gera um custo adicional para a indústria. A pintura em pó é indicada para superfícies que ficarão expostas a intempéries e é considerada uma matéria-prima com elevado valor agregada. Assim, aplicando uma camada em microns além da indicada no boletim técnico da tinta estará acrescentando um custo desnecessário ao processo de pintura. Caracteriza-se por um estudo de caso, o qual se realizou em empresa do ramo metal mecânico localizada no noroeste do estado do Rio Grande do Sul. Os dados da espessura de camada de tinta foram coletados em um período de 30 dias, foram monitorados setenta e três produtos durante a pesquisa, e neste artigo apresentamse os resultados do produto que possui maior valor agregado e a produção ocorre em maior quantidade. Os resultados apontam uma aplicação em excesso de tinta de 31,98\%, resultando em uma perda de faturamento de $R \$ 2,65$ por peça.
\end{abstract}

Palavras-chave: camada de tinta; tinta em pó; custo oculto.

\section{Introdução}

As empresas nacionais estão inseridas em um mercado extremamente competitivo, para a permanência das mesmas no mercado é necessário que elas busquem a redução de custos. A aplicação de excesso de tinta em pó, além de causar problemas de qualidade nas peças, também gera um grande desperdício de matéria-prima, e consequentemente de lucros para a empresa. 
Na empresa pesquisa, semanalmente é realizado o controle de qualidade dos itens pintados, através de testes em corpos de prova após a cura. Estes corpos de prova recebem tratamento de superfície igual às demais peças e são pintadas juntamente com as peças da linha de produção. No laboratório de metrologia da empresa são realizados os testes de espessura seca de camada de tinta, aderência e teste de cura. Além destes, anualmente são realizados testes de flexibilidade, brilho, resistência à névoa salina, resistência ao impacto e resistência à umidade em laboratório terceirizado. Os resultados dos testes internos de espessura de camada de tinta apontam para o excesso de camada de tinta.

Pesquisas realizadas referentes ao excesso de camada de tinta são abordadas principalmente pelo ponto de vista da qualidade, e consequente pela redução dos custos de produção. O trabalho de Lombardi et al (2010), teve por objetivo averiguar a variabilidade da camada seca de tinta, o resultado apresentou grandes desperdícios de tinta e retrabalho, mas não foram levantados dados monetários referentes as perdas. Os trabalhos de Soares (2003) e Hessler (2008) apresentam a aplicação do Controle Estatístico no setor de pintura, com a implantação de melhorias para a redução da camada de tinta, evidenciando a melhoria da qualidade no processo de pintura. Hessler (2008), também fez um levantamento, após a implantação das melhorias, sobre os ganhos financeiros que obtiveram com a diminuição do consumo de matéria-prima.

Após a análise dos trabalhos de Soares (2003), Lombardi et al (2010), Hessler (2008), observa-se que a aplicação de excesso de camada de tinta é comum nas empresas. A aplicação do excesso de camada de tinta nas empresas é um problema, pois o cliente paga somente a quantidade de tinta que está especificado no projeto/norma, e o excesso de matéria-prima utilizada no processo gera um custo adicional que será pago pela própria empresa. Além desse custo adicional, existe a possibilidade do excesso causar problemas de qualidade nas peças, acarretando em nãoconformidades que geram um custo adicional ao processo.

Portanto, o objetivo da pesquisa é analisar o custo gerado a partir da aplicação em excesso de tinta em pó em peças fabricadas em aço. Saber o percentual de perda que ocorre é importante para saber o quanto se pode investir em melhorias neste setor.

\section{Fundamentação teórica}

\subsection{Processo de pintura em pó}

De acordo com Soares (2003), o aço é uma das principais matérias-primas nas indústrias, devido a sua composição ele facilmente sofre corrosão, para evitar a corrosão é necessária uma camada de revestimento de alta qualidade. Um dos modos de proteger contra a corrosão é a aplicação de tinta, a qual pode ser tinta líquida ou em pó, além de impedir a corrosão, a pintura também proporciona estética a peça. 
A composição das tintas em pó é de $100 \%$ de matéria-prima sólida (SILVA, 2009). A aplicação da tinta em pó tem aumentado muito nos últimos anos, pois é uma forma de conseguir acabamento nas peças de alta qualidade, além de aumentar as taxas de produção, reduzir custos e estar em conformidade com os padrões ambientais (LIBERTO, 2003). Tintas líquidas requerem a necessidade do uso de solventes, esses solventes necessitam de ventilação, filtragem e sistemas de controle de volatilidade, enquanto que nas tintas em pó não existe essa necessidade (LIBERTO, 2003).

A aplicação da tinta em pó geralmente é realizada por meio de aplicação eletrostatica, as partículas finamente moídas de pigmentos e resinas são eletrostaticamente carregadas e pulverizadas em uma parte de metal (UTECH, 2002). Este processo pode ser manual ou automático, com uma ampla variedade de equipamentos disponível para uso em pequena ou grande escala. As peças a serem revestidas são neutras, a carga de partículas projetada adere à peça e são submetidas ao aquecimento. Durante o processo de aquecimento, o pó derrete e cria um revestimento uniforme e liso, este processo é conhecido como cura da tinta em pó. O resultado é uniforme, durável e de alta qualidade no acabamento, revestimentos em pó proporcionam ótima resistência a corrosão, impactos e resistência a abrasão, bem como fixação do brilho (UTECH, 2002; LIBERTO, 2003).

Em relação à cura da tinta em pó, é recomendado que a peça permaneça durante 10 minutos a $200^{\circ} \mathrm{C}$ na estufa para que seja totalmente curada, a espessura da camada seca ideal de tinta é definida no Boletim Técnico de cada tinta, pois varia de acordo com cada tipo de tinta (SILVA, 2009). A aplicação da tinta em pó pode ser realizada em geral em substratos metálicos, como aço, aluminío, cobre e latão, mas também pode ser aplicado sobre materiais cerâmicos como vidro e telhas, desde que haja recomendação técnica (SILVA, 2009).

Para a medição de espessura de camada de tinta é utilizado um aparelho conhecido como medidor de espessura de camada, a análise é realizada por um método não destrutivo, podendo ser realizado em peça acabadas, sem danificar as mesmas. Estão disponíveis no mercado medidores digitais e analógicos.

Conforme Utech (2002), embora os custos dos equipamentos e materiais são similares entre aplicações em pó e líquida, a aplicação de pó possui inúmeras vantagens econômicas, as quais são: menor rejeição; menor espaço físico necessário; menor desperdício de materiais; baixos custos de energia; treinamento inferior e menores custos trabalhistas; redução dos custos de eliminação de resíduos; mais eficiência nas operações de limpeza; e acabamentos mais uniformes.

\subsection{Gestão estratégica de custos}

De acordo com Bruni e Famá (2008) e Perez et al (2008), os custos representam os gastos relativos aos recursos consumidos na produção de outros bens e serviços. Ainda, para Bruni e Famá 
(2008), custos são como medidas monetárias dos sacrifícios com os quais uma empresa tem que arcar a fim de atingir seus objetivos, portanto, os custos estão relacionados ao processo de produção de bens e serviços.

O surgimento da contabilidade de custos decorreu da necessidade de informações precisas para tomada de decisão correta após a Revolução Industrial, por volta de 1760 (BRUNI e FAMÁ, 2008).

Para Herculano (2009), a necessidade das empresas em aperfeiçoar seus mecanismos de planejamento e controle surgiu com intensificação da concorrência. Constatando-se que as informações contábeis, financeiras e de vendas poderiam constituir um importante subsídio de apoio para execução das atividades relacionadas com o processo de tomada de decisão e de planejamento e controle (BRUNI e FAMÁ, 2008).

Assim, a contabilidade de custos transformou-se, gradativamente, em um sistema de informações de vital importância para a gestão empresarial (HERCULANO, 2009).

\subsection{Custos de produção: custos fixos e variáveis}

O controle dos custos de produção é um dos objetivos da contabilidade de custos (PEREZ et al, 2008). Uma vez que a contabilidade de custos integra a contabilidade gerencial, e a mesma é necessária por duas razões: gerencial e, fiscal e societária.

A necessidade gerencial refere-se aos controles extracontábeis e não existe a preocupação em atender os princípios contábeis ou as diversas regulamentações legais e fiscais (PEREZ et al, 2008). Ainda, destaca Perez et al (2008), a necessidade fiscal e societária trata das exigências feitas pelas autoridades fiscais e pela Legislação Comercial e Societária, assim a empresa deve manter uma contabilidade de custos integrada e coordenada com o restante da escrituração mercantil.

Através do controle dos custos de produção a indústria tem a possibilidade de identificar e controlar seus custos (PEREZ et al, 2008). Para este mesmo autor, controlar significa, após conhecer dada realidade, compará-la com algo que se esperava analisar as possíveis diferenças, identificar as causas e tomar decisões com vistas a eliminar ou reduzir tais diferenças.

Quanto ao comportamento em relação às variações nos volumes de produção e de vendas, permite classificar os custos em: fixos, variáveis, semifixos e semi-variáveis (PEREZ et al, 2008).

De acordo com Leone (1997), os custos fixos permanecem inalterados qualquer que seja o volume de produção. Para Perez et al (2008), os custos fixos se mantem constantes dentro de determinada capacidade instalada, pois independem do volume de produção, não variam caso a produção seja maior ou menor, mesmo que a produção seja zero, os custos fixos se mantem.

Já os custos variáveis, possuem uma relação direta com o volume de produção, quanto maior for a produção maior serão os custos variáveis (PEREZ et al, 2008). Se não houver quantidade 
produzida, o custo variável será nulo (LEONE, 1997). Ainda, destaca Leone (1997), que os custos variáveis devem ser analisados com respeito às quantidades consumidas na produção e não aquelas que foram adqueridas.

Os custos semifixos, são aqueles custos que são fixos em determinado patamar, passando a ser variáveis quando este patamar for superado. Quando o valor for excedido, o valor torna-se variável de acordo com o consumo, e quando é inferior mantem o valor (BRUNI e FAMÁ, 2008). Os custos semivariáveis, correspondem aos custos variévis que não acompanham linearmente a variação da produção, mas aos saltos, mantendo-se fixos dentro de centros limites (BRUNI e FAMÁ, 2008).

Bruni e Famá (2008), ilustraram a evolução dos custos de acordo com sua classificação, conforme a Figura 1.

Figura 1 - Evoluções dos diferentes custos

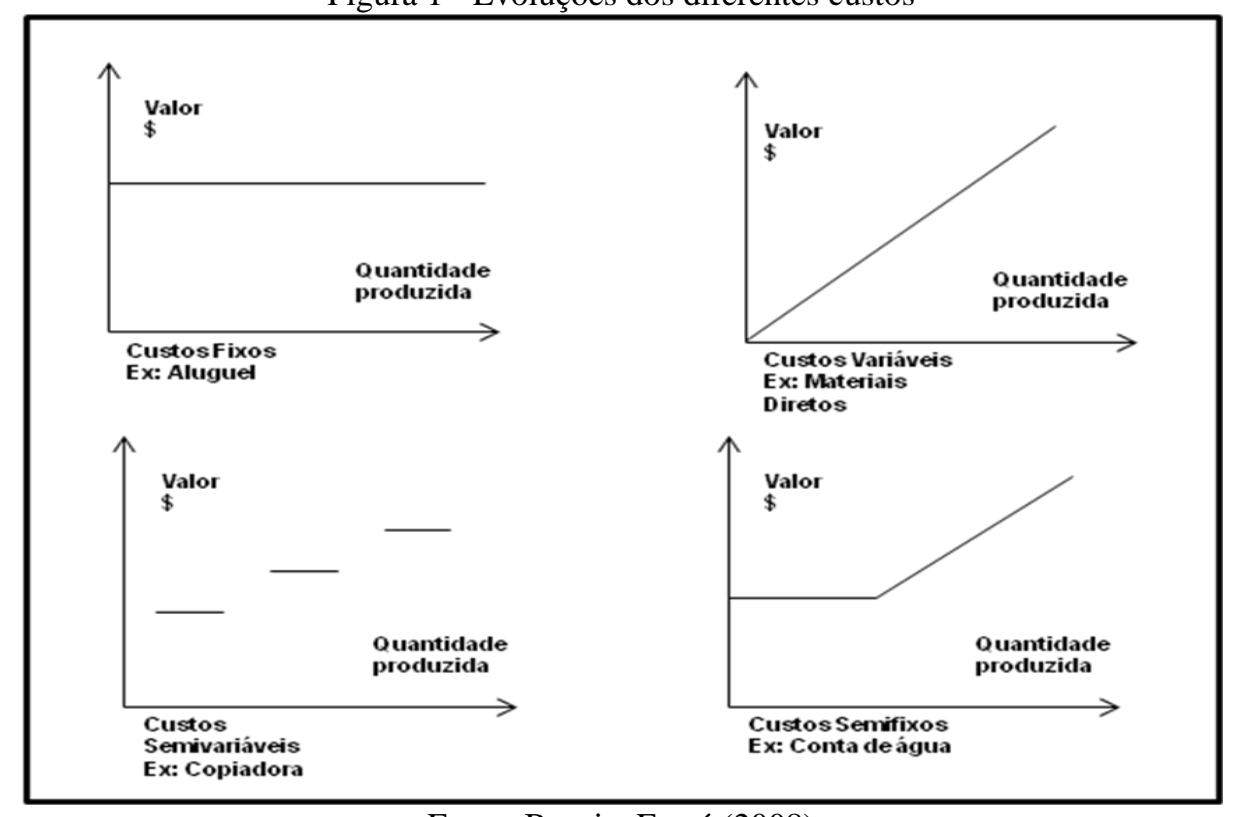

Fonte: Bruni e Famá (2008)

\subsection{Custos ocultos}

Culto oculto é qualquer custo que não esteja aparente na contabilidade padrão, mas que seja importante para o processo de produção (FUREDY, 2005). Para Herculano (2008), custos ocultos ou mal estruturados são aqueles custos que não foram identificados e, consequentemente, não foram mensurados. Deste modo, compreende-se que o levantamento dos cultos ocultos é importante para as empresas, pois as mesmas podem estar perdendo grandes lucros sem tomar conhecimento deste fato ou até mesmo obtendo prejuízos em seu processo sem conhecerem as verdadeiras causas custo oculto.

De acordo com Freitas e Severiano Filho (2007), pesquisas sobre custos ocultos são de interesse do mundo moderno, no entanto a literatura sobre o tema é escassa. Conforme Lima (1991), 
os custos ocultos são formados por: sobrecargas (sobresalários, sobretempo, sobreconsumos) e por não produtos (não produção e não criação de potencial estratégico). Esses custos ocultos podem ser classificados e decompostos nos seguintes elementos:

- Custos de absenteísmo;

- Custos de acidente de trabalho;

- Custos de rotação de pessoal;

- Custos de não qualidade; e

- Custos ligados à produtividade direta.

No custo de não qualidade está envolvido, o custo comercial da devolução e da troca e do lote defeituoso, custo de produção dos retoques e dos retrabalhos. Os custos ligados a produtividade são definidos como sobreconsumo de matérias-primas e demais materiais, não produção devido a parada de máquina, menor produtividade do trabalho humano (LIMA, 1991). Neste trabalho serão abordados os custos ocultados ligados à produtividade, ou seja, o sobreconsumo de matéria-prima em um setor da empresa.

O motivo pelo qual as empresas dificilmente contabilizam os custos ocultos é devido a estes se encontrarem desfragmentados e espalhados. Estes fragmentos de custos quando recolhidos, tornam-se valores exorbitantes (LIMA, 1991). Neste sentido, a busca constante pela melhoria contínua nas empresas ou a inserção de metodologias de qualidade como, por exemplo, Seis Sigma podem contribuir para a redução dos custos ocultos.

De acordo com Bornia (2002), as classificações dos custos ocultos estão relacionadas com as perdas existentes no processo, pois o desperdício é fonte de perda. Na maior parte dos sistemas de mensuração é considerado apenas os custos diretos e os indiretos, desprezando os desperdícios e gerando custos ocultos, deste modo, a mensuração dos desperdícios e das atividades que não agregam valor aos produtos, é uma das funções mais importantes, pois com estes dados é possível verificar qual a quantia que não colabora no processo produtivo e deste modo, tem-se as condições para definir onde priorizar e dirigir esforços para a melhoria nos pontos em que se obterá um retorno maior.

De acorco com Shingo (1996), as perdas no processo produtivo podem ser por:

- Superprodução: ocorre no momento em que a produção é maior que a necessidade, ou então antes que o produto seja necessário;

- Transporte: refere-se ao transporte entre seções que não agrega valor ao produto que está sendo manufaturado; 
- Processamento: ocorre quando há uma atividade desnecessária para que o produto adquira suas características;

- Fabricação de produtos defeituosos: quando da produção de itens que não atendam a especificação do projeto;

- Movimento: quando existe a presença de movimentos desnecessários na realização de determinadas atividades;

- Espera: é formado pela capacidade ociosa, quando há trabalhadores e instalações parados;

- Estoque: quando o produto fica parado por algum motivo.

Para melhor definir essas perdas Kardec (2002) apud Herculano, (2008), apresenta a classificação para serviços de engenharia, conforme Quadro 1.

Quadro 1 - Tipos de perdas quanto ao resultado de serviço de engenharia

\begin{tabular}{|c|c|}
\hline Tipo & Descrição \\
\hline Quebras & Perdas de matéria-prima não passíveis de recuperação. \\
\hline Sobras & Perdas de materiais que não foram utilizados na composição do produto. \\
\hline Retrabalhos & Perdas advindas do reprocessamento de materiais semiacabados ou produtos fora das \\
& especificações. \\
\hline Refugos & $\begin{array}{c}\text { Materiais semiacabados ou produtos fora das especificações requeridas pelo processo ou } \\
\text { pelos clientes, para os quais não haja a possibilidade ou não sejam vantajosos os } \\
\text { retrabalhos. }\end{array}$ \\
\hline Ociosidades & $\begin{array}{c}\text { Disponibilidade de tempo dos recursos não aproveitados integralmente para agregar valor } \\
\text { ao produto. }\end{array}$ \\
\hline Ineficiências & Perdas oriundas dos desvios ocorridos durante a execução do processo com relação às \\
&
\end{tabular}

Fonte: Kardec (2002 apud HERCULANO, 2008)

\section{Método da pesquisa}

Em relação ao método de procedimento o trabalho caracteriza-se por um estudo de caso, pois a pesquisa realizou-se em uma indústria metal-mecânica, aqui denominada como Indústria MetalFab, localizada no Noroeste do estado do Rio Grande do Sul, desenvolvida no período de agosto a novembro de 2012. Esta indústria atua principalmente no ramo de estampagem de componentes metálicos e conformação de tubos, soldagem e pintura de conjuntos para montadoras de máquinas agrícolas. A sua área industrial possui dez centros de trabalhos, sendo eles:

- Corte da matéria-prima;

- Corte de tubo;

- Recorte com puncionadeira;

- Recorte com laser; 
- Dobra de chapas;

- Dobra de tubos;

- Estampagem;

- Solda dos conjuntos;

- Rebarbagem; e

- Pintura.

A pesquisa foi efetivamente aplicada neste último centro de trabalho, onde foram realizados os testes e a observação dos fenômenos de pintura em pó da indústria.

As técnicas correspondem à parte prática da pesquisa (MARCONI e LAKATOS, 2011), neste sentido utilizaram-se neste estudo as seguintes técnicas: pesquisa bibliográfica, observação e testes. A pesquisa bibliográfica possibilitou a revisão e aprofundamento da literatura existente sobre o tema, permitindo um domínio maior sobre o assunto. Utilizou-se para tanto livros, revistas e normas.

Para a coleta dos dados utilizou-se uma folha de verificação, os dados foram levantados durante trinta dias, monitorando de maneira full-time e registrando o valor da camada de tinta, em microns $(\mu)$, encontrada em cada produto que passava pelas cabines de pintura em pó e após pela estufa de secagem. A camada seca de tinta foi mensurada com equipamento conhecido como medidor de espessura de camada digital, devidamente calibrado. Foram escolhidos, de forma aleatória, dez pontos de coleta da camada de tinta para cada produto e para cada tipo de produto foram monitoradas dez unidades. Estes dados foram tabulados e analisados com o auxílio do Microsoft Excel. Neste trabalho serão demonstradas as perdas por excesso de camada de tinta de somente um produto, o qual será chamado de Produto Y. O Produto Y é o produto com maior valor agregado e é produzido em maior quantidade.

Além disso, registrou-se em vídeo o processo de como o operador aplicou a tinta em pó na peça, possibilitando a observação do modo da aplicação, e a comparação com a camada de tinta encontrada com o valor especificado no boletim técnico da tinta e exigência dos padrões do cliente.

\section{Análise dos resultados}

A Indústria MetalFab possui o processo de pintura em pó e fornece o serviço de pintura conforme as cores especificadas no projeto de cada produto, oriundas dos seus clientes. No Quadro 2, estão relacionadas às cores monitoradas durante a pesquisa e seus limites de camada, conforme as especificações encontradas no boletim técnico de cada tinta. 
Quadro 2 - Espessura de camada de tinta

\begin{tabular}{|c|c|c|}
\hline Cor da Tinta & Camada mínima $(\boldsymbol{\mu})$ & Camada máxima $(\boldsymbol{\mu})$ \\
\hline Preto semi-fosco & 60 & 90 \\
\hline Preto alto-brilho & 60 & 80 \\
\hline Verde & 60 & 90 \\
\hline Cinza A & 60 & 80 \\
\hline Cinza B & 60 & 80 \\
\hline Vermelho & 50 & 70 \\
\hline Primmer & 30 & 40 \\
\hline
\end{tabular}

Fonte: Indústria MetalFab (2011)

É necessário controlar a camada de tinta conforme especificações técnicas, pois além de variar a tonalidade da cor, se aplicada camada muito abaixo da especificada não terá a cobertura necessária, causando oxidação da peça, como também, se a camada da tinta ficar muito acima da indicada, pode causar desplacamento da tinta (SILVA, 2009).

Assim, assumiu-se para o estudo de caso a média entre a camada mínima e a camada máxima da tinta. Dentre os setenta e três produtos monitorados durante a pesquisa, serão apresentados os resultados do produto que tem maior valor agregado e a produção é em maior quantidade pela Indústria MetalFab, denominado como Produto Y.

A cor da tinta em pó utilizada para o Produto Y é verde. E conforme apresentado no Quadro 2, a especificação da camada da tinta verde é de 60-90 ( $\mu$ ).

No Quadro 3, estão demonstrados os valores de espessura de camada de tinta encontrados em 10 peças do Produto Y e em cada peça foram medidos 10 pontos diferentes.

Quadro 3 - Camada de tinta encontrada no produto Y

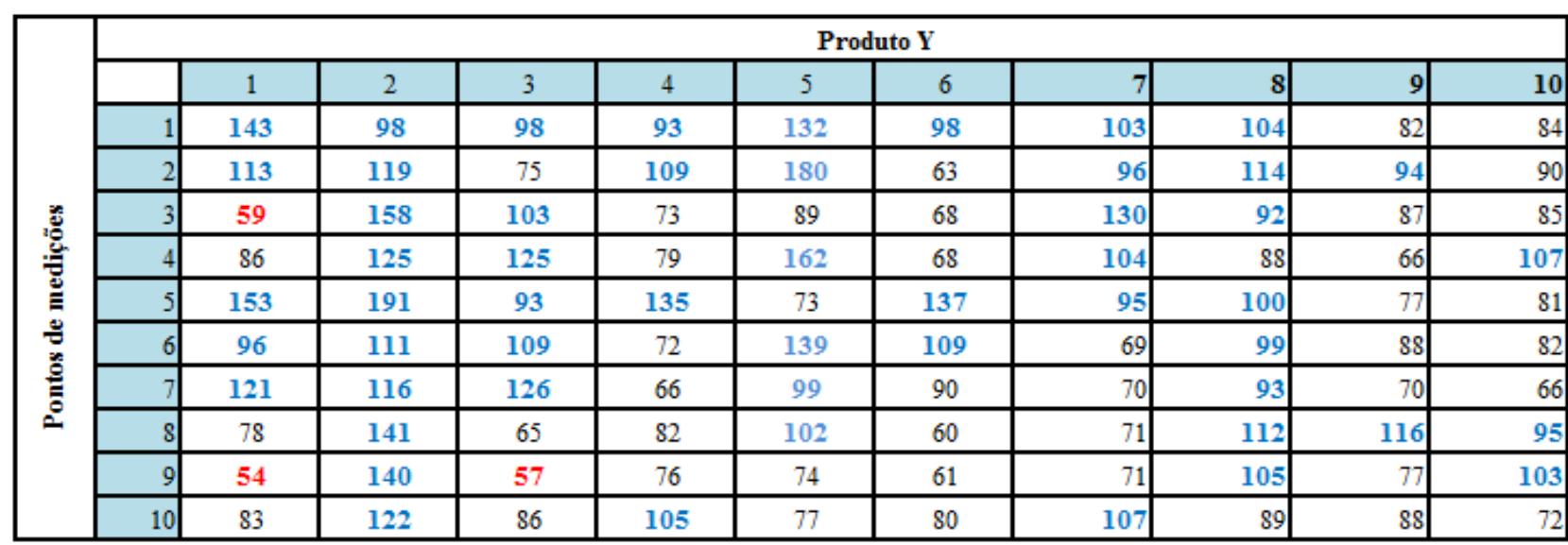

Fonte: Elaborado pelos autores

Os valores em azuis no Quadro 3 são as camadas encontradas acima da camada máxima de $90(\mu)$. Já os valores em vermelho são as camadas abaixo da camada mínima de $60(\mu)$. E os demais valores encontram-se dentro dos limites inferior e superior.

Após o levantamento dos dados fez-se um histograma para verificar a distribuição dos dados de espessura de camada de tinta, o qual está representado na Figura 2. Como se pode observar a distribuição dos dados não é normal. 
Figura 2 - Histograma da mensuração da camada de pintura do Produto Y

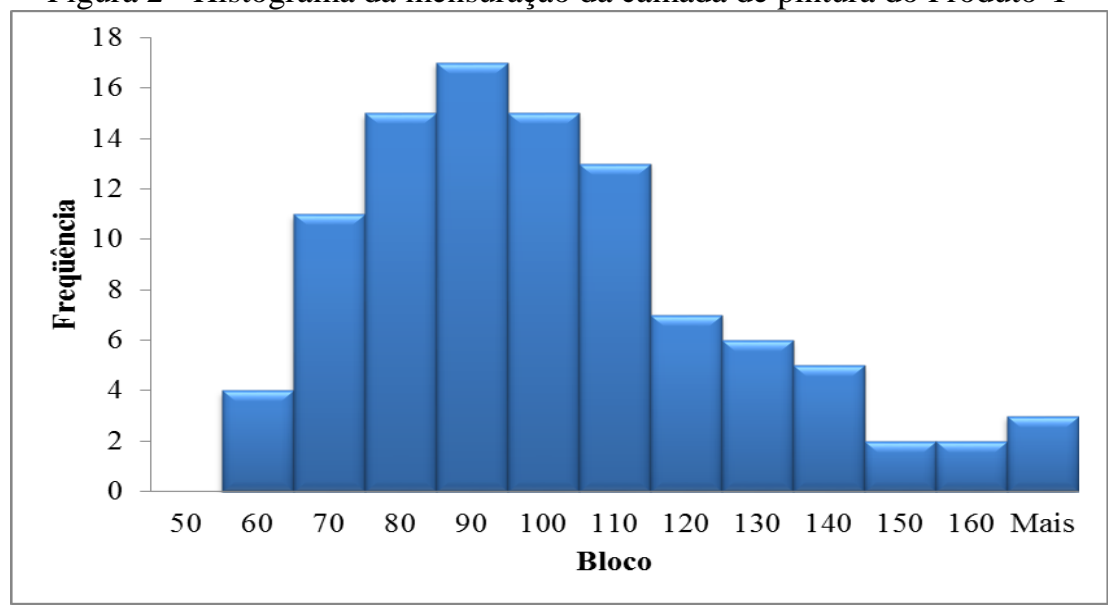

Fonte: Elaborado pelos autores

Tabela 1 - Tabela de frequência da camada de pintura do produto Y

\begin{tabular}{rr}
\hline \multicolumn{1}{c}{ Bloco } & Freqüencia \\
\hline 54 & 1 \\
67,7 & 9 \\
81,4 & 21 \\
95,1 & 23 \\
108,8 & 18 \\
122,5 & 12 \\
136,2 & 6 \\
149,9 & 5 \\
163,6 & 3 \\
177,3 & 0 \\
Mais &
\end{tabular}

Fonte: Elaborado pelos autores

Aplicando um histograma, Figura 2, sobre a mensuração das camadas coletadas e analisando a tabela de frequência, Tabela 1, percebe-se que o processo apresenta-se fora das tolerâncias, tendendo para direita do gráfico.

A Figura 3 ilustra de forma objetiva a posição das camadas de pintura mediante os seus limites. Verifica-se que o valor da espessura da camada de tinta se encontra acima da tolerância máxima de $90 \mu$. 


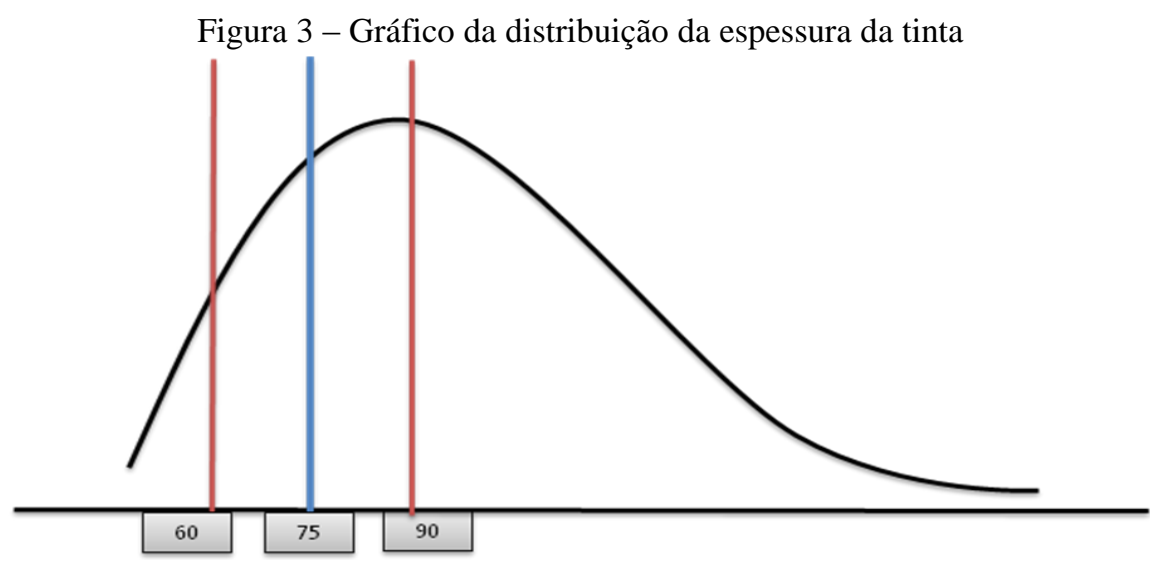

Fonte: Elaborado pelos autores

E é o custo dessa aplicação de camada de tinta acima da tolerância que se enfoca neste estudo de caso.

Para a mensuração dessa aplicação de tinta em pó excedente sobre o Produto Y, calculou-se utilizando a Fórmula (1) a camada média de tinta, de acordo com os limites máximos e mínimos apresentados no Quadro 1.

$$
\text { Camada_média }=\left(\frac{\text { Camada_máxima }+ \text { Camada_mínima }}{2}\right)
$$

$$
\text { Camada_média }=\left(\frac{90+60}{2}\right)=75 \mu
$$

A partir da camada média de 75 ( $\mu$ ), Fórmula (2), calculou-se a camada excedente, sendo:

$$
\text { Camada_excedente }=(\text { Camada_encontrada }- \text { Camada_média })
$$

Aplicando a Fórmula (3), sobre os valores do Quadro 2, encontrou-se a camada excedente de tinta em pó, os quais se encontram no Quadro 4. 
Quadro 4 - Camada de tinta após a aplicação da Fórmula 3

\begin{tabular}{|c|c|c|c|c|c|c|c|c|c|c|c|}
\hline & & \multicolumn{10}{|c|}{ Produto Y } \\
\hline \multirow{11}{*}{ 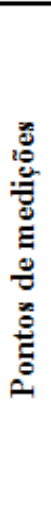 } & & 1 & 2 & 3 & 4 & 5 & 6 & 7 & 8 & 9 & 10 \\
\hline & 1 & 68 & 23 & 23 & 18 & 57 & 23 & 28 & 29 & 7 & 9 \\
\hline & 2 & 38 & 44 & & 34 & 105 & & 21 & 39 & 19 & 15 \\
\hline & 3 & & 83 & 28 & & 14 & & 55 & 17 & 12 & 10 \\
\hline & 4 & 11 & 50 & 50 & 4 & 87 & & 29 & 13 & & 32 \\
\hline & 5 & 78 & 116 & 18 & 60 & & 62 & 20 & 25 & 2 & 6 \\
\hline & 6 & 21 & 36 & 34 & & 64 & 34 & & 24 & 13 & 7 \\
\hline & 7 & 46 & 41 & 51 & & 24 & 15 & & 18 & & \\
\hline & 8 & 3 & 66 & & 7 & 27 & & & 37 & 41 & 20 \\
\hline & 9 & & 65 & & 1 & & & & 30 & 2 & 28 \\
\hline & 10 & 8 & 47 & 11 & 30 & 2 & 5 & 32 & 14 & 13 & \\
\hline
\end{tabular}

Fonte: Elaborado pelos autores

O somatório das camadas do Quadro 4 é igual a $\Sigma=2399(\mu)$. Isso equivale a 31,98\% de tinta aplicada em excesso sobre o Produto Y.

Também se coletou dados técnicos sobre o Produto Y, fornecidos pela empresa, que estão apresentados no Quadro 5.

\begin{tabular}{|l|c|}
\hline \multicolumn{2}{|c|}{ Quadro 5 - Dados referente ao produto Y } \\
\hline Área de pintura do Produto Y & Valor \\
\hline Quant. De tinta s/ perdas no processo & $2,77 \mathrm{~m}^{2}$ \\
\hline Perda de tinta no processo & $249 \mathrm{~g}$ \\
\hline Quant. De tinta necessária p/ Produto Y & $10 \%$ \\
\hline Quant. De MP em 1 caixa de tinta a pó & $273,9 \mathrm{~g}$ \\
\hline Total de Produto Y pintados com 1 caixa de tinta a pó & $20.000 \mathrm{~g}$ \\
\hline Custo de 1 caixa de tinta a pó & 73 unidades \\
\hline Custo mão-de-obra & $\mathrm{R} \$ 690,00$ \\
\hline Custo total do processo de pintura do Produto Y & $\mathrm{R} \$ 15,80$ \\
\hline
\end{tabular}

Fonte: Elaborado pelos autores

A partir dos dados técnicos coletados na Indústria MetalFab foi possível comparar com os valores de perda ocasionados pela aplicação em excesso de tinta em pó sobre o Produto Y. Assim, apresenta-se o Quadro 6. 


\begin{tabular}{|l|c|}
\hline \multicolumn{2}{|c|}{ Quadro 6 - Dados técnicos referentes ao produto Y } \\
\hline Área de pintura do Produto Y & Valor \\
\hline Quant. de tinta s/ perdas no processo & $2,77 \mathrm{~m}^{2}$ \\
\hline Perda de tinta no processo & $249 \mathrm{~g}$ \\
\hline Aplicação de tinta em excesso & $10 \%$ \\
\hline Quant. De tinta necessária p/ Produto Y & $31,98 \%$ \\
\hline Quant. De MP em 1 caixa de tinta a pó & $353,55 \mathrm{~g}$ \\
\hline Total de Produto Y pintados com 1 caixa de tinta a pó & $20.000 \mathrm{~g}$ \\
\hline Custo de 1 caixa de tinta a pó & $57 \mathrm{unidades}$ \\
\hline Custo mão-de-obra & $\mathrm{R} \$ 690,00$ \\
\hline Custo total do processo de pintura do Produto Y & $\mathrm{R} \$ 15,80$ \\
\hline
\end{tabular}

Fonte: Elaborado pelos autores

Analisando os dados, nota-se que com a aplicação de tinta em excesso a quantidade de tinta necessária para o Produto Y passou de 273,9 gramas para 353,55 gramas e, consequentemente, elevando o custo da pintura de $\mathrm{R}$ \$ 25,25 (Quadro 5) para $\mathrm{R}$ \$27,91 (Quadro 6).

Quadro 7 - Custos referentes ao processo de pintura do Produto Y

\begin{tabular}{|l|c|}
\hline \multicolumn{1}{|c|}{ Descrição } & Total (un) \\
\hline Valor pago pelo cliente & $\mathrm{R} \$ 35,38$ \\
\hline Custo total teórico & $\mathrm{R} \$ 25,25$ \\
\hline Custo total real & $\mathrm{R} \$ 27,91$ \\
\hline & $\mathrm{R} \$ 10,13$ \\
\hline Ganho desejado & $\mathrm{R} \$ 7,47$ \\
\hline Ganho obtido & $\mathrm{R} \$ 2,65$ \\
\hline Perda de faturamento & $\mathrm{R} \$ 5.539,90$ \\
\hline Total perda de faturamento ano 2011 & \\
\hline
\end{tabular}

Fonte: Elaborado pelos autores

Assim, a diferença entre o ganho desejado e o ganho obtido por unidade do Produto Y é de R\$ 2,65, conforme Quadro 7. Considerando que a produção no ano de 2011 foi de 2088 unidades do Produto $\mathrm{Y}$, o total de perda de faturamento anual foi de $\mathrm{R} \$ 5.539,90$. Neste dado não estão contabilizados os custos de não qualidade, o que agrega uma perda ainda maior no faturamento da empresa.

Como sugestão de melhorias: treinamento para os funcionários da pintura, troca das pistolas de pintura que podem influenciar na camada de tinta.

Ainda, a Indústria MetalFab por ser uma fornecedora de peças para montadoras de máquinas agrícolas, onde o mercado está cada vez mais competitivo, está submetida a determinação do preço de venda pelas montadoras, ou seja, elas determinam o preço que vão pagar por seus produtos e, consequentemente, o percentual de lucratividade para o fornecedor. Conforme representado no Gráfico 1. 


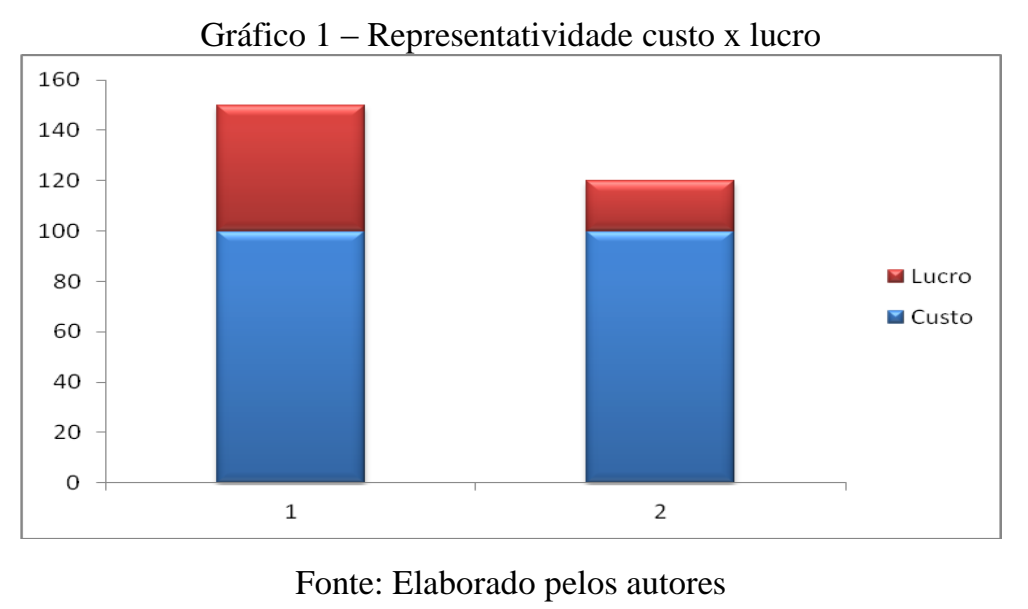

A coluna 1 do Gráfico 1, representa o preço ditado pelos fornecedores e na coluna 2 do Gráfico 1 representa o preço determinado pelos clientes, sendo a situação atual do mercado agrícola. Assim, o fornecedor é forçado a buscar melhorias para afinar seus processos produtivos, diminuindo as perdas e maximizando o uso dos recursos, a fim de minimizar custos e aumentar sua lucratividade.

A perda de faturamento $\mathrm{R} \$ 2,65$ por cada Produto $\mathrm{Y}$ representa a parte de lucratividade do Gráfico 1, aqui indicada na cor em vermelho.

\section{Considerações finais}

Com este estudo foi possível identificar e analisar o custo gerado a partir da aplicação em excesso de tinta em pó em peças fabricadas em aço. Os cálculos e as análises apontaram uma aplicação de excesso de tinta de $31,98 \%$ por unidade produzida do Produto Y. Resultando em uma perda de faturamento de $\mathrm{R} \$ 2,65$ por unidade vendida.

A empresa analisada tem como principais clientes montadoras de máquinas agrícolas, neste ramo o modelo de produção apresenta baixos lotes de produção e grande variedade de peças. Neste ambiente a empresa teve uma perda anual no produto analisado de $\mathrm{R} \$ 5.539,90$, no qual não foram contabilizados os custos ocultos de não qualidade, somente os custos relativos a perdas de produtividade.

Sendo que ela produz mais de 5000 peças diferentes que passam pelo processo de pintura, conclui-se que a abordagem de Lima (1991) é verdadeira, quando se refere que os custos ocultos ao serem contabilizados e somados geram perdas exorbitantes. Melhorar o processo de pintura é o próximo passo para a empresa se manter no mercado, para tanto é necessário alguns investimentos no processo de pintura, como disponibilizar treinamento aos pintores, trocar os bicos das pistolas de pintura e melhorar os compressores de ar.

No presente estudo verificou-se a importância de analisar os processos produtivos da indústria, a fim de obter melhorias contínuas e consequentemente reduzir as perdas. Enxergar os 
custos ocultos não é uma tarefa fácil para quem está envolvido no processo diário. Mas, é uma análise que precisa ser realizada para melhorar os rendimentos e tornar a empresa mais lucrativa e competitiva diante do cenário que se encontra.

Como sugestão de trabalhos futuros tem se a verificação da eficácia após a implantação das melhorias contínuas, através de uma nova coleta de dados de espessura de camada seca de tinta, para verificar o montante de ganhos que se obteve.

\section{Abstract}

The need to reduce costs in companies is a practical must for the maintenance of those on the market currently so competitive. In this work are presented the results of a survey in an industry in mechanic metal branch, which aimed to analyze the additional cost generated by the application of excess ink powder. The surplus applying powder paint to steel fabricated parts, besides causing quality problems generates an additional cost to the industry. The powder painting is recommended for surfaces that will be exposed to the elements and is considered a raw material with high aggregate value. Thus, applying a layer in microns than indicated in the technical ink bulletin will be adding an unnecessary cost to the painting process. It is characterized as case study, which was conducted in a company of mechanical metal branch located in the northwest of the state of Rio Grande do Sul. The data on the thickness of the paint layer were collected over a period of 30 days, were monitored seventy and three products during the research, and this paper presents the results of the product that has higher added value and production occurs in greater quantities. The results indicate an application in ink excess of $31.98 \%$, resulting in a loss of revenue of R \$ 2.65 per piece.

Key-words: ink layer; ink powder; hidden cost.

\section{Referências}

BORNIA, A. C. 2002. Análise gerencial de custos em empresas modernas. Porto Alegre: Bookman.

BRUNI, A. L., FAMÁ, R. 2008. Gestão de custos e formação de preço: com aplicações na calculadora HP $12 \mathrm{C}$ e Excel. 5 ed. São Paulo: Atlas.

FREITAS, J. B., SEVERIANO FILHO, C. 2007. Apreciação dos custos ocultos do processo sucroalcooleiro em uma usina de álcool na Paraíba. Revista Gestão Industrial. v. 3, n. 01, p. 52-63. cross ref

FUREDY, C. 2002. Organic waste at low cost: dilemmas of a transition period. Urban Agriculture Magazine. v. 6, p. 38-39.

HERCULANO, A. S. 2009. Mensuração e avaliação dos custos ocultos no setor de manutenção industrial de uma mineradora: impacto gerencial no ciclo de vida. 2009. 140 f. Dissertação (Mestrado em Engenharia de Produção) Universidade Federal da Paraíba, João Pessoa.

HESSLER, C. V. 2008. Aplicação de controle estatístico de processo na empresa "Metasa" como uma ferramenta de competitividade. 2008. 120 f. Dissertação (Mestrado em Administração) - Universidade de Caxias do Sul, Caxias do Sul, 2008.

INDÚSTRIA METALFAB. 2001. Instrução de trabalho 80: camada de tinta para o processo de pintura em pó. Rev. 04.

LEONE, G. S. G.. 1997. Curso de contabilidade de custos. Editora Atlas, São Paulo.

LIBERTO, N. 2003. User's Guide to powder coating. 4 ed. United States of America: SME - Society of Manufacturing Engineers. 
LIMA, M. A. A. 1991. A Estrutura e as Ferramentas da Intervenção-pesquisa Sócio-economica nas Empresas e Demais Organizações. Revista de Administração de Empresas. v. 31, n 01, p. 21-30. cross ref

LOMBARDI, T. et al. 2010. Análise estatística da camada seca de pintura: o caso Nova JVA. In: Simpósio de engenharia de produção, 17., 2010, Bauru. Anais... Bauru: UFSCAR, 2010. Disponível em:

<http://www.simpep.feb.unesp.br/anais.php>. Acesso em: 12 nov. 2012.

MARCONI, M. A., LAKATOS, E. M. 2011. Metodologia do trabalho científico. 7 ed. São Paulo: Atlas.

PEREZ, J. H. et al. 2008. Gestão estratégica de custos. 5 ed. 2 reimpr. São Paulo: Atlas.

SHINGO, S. 1996. O sistema Toyota de produção: do ponto de vista da engenharia de produção. 2 ed. Porto Alegre: Bookman.

SILVA, S. D. 2009. Pintura industrial em pó: informações técnicas DT-13. 3 ed. Guaramirim: Tintas Weg.

SOARES, V. L. M. P. 2003. Aplicação e implantação do controle estatístico de processo em pintura industrial. Dissertação (Mestrado em Engenharia de Produção). 2003. 114 f. Universidade Federal de Santa Catarina, Florianópolis.

UTECH, B. 2002. A guide to High performance Powder Coating. United States of America: SME - Society of Manufacturing Engineers.

\section{Dados dos autores}

Nome completo: Loana Wollmann Taborda

Filiação institucional: Universidade Federal de Santa Maria - UFSM

Departamento: Programa de Pós Graduação em Engenharia de Produção - PPGEP

Função ou cargo ocupado: Mestranda

Endereço completo para correspondência (bairro, cidade, estado, país e CEP):

Universidade Federal de Santa Maria, Programa de Pós-Graduação em Engenharia de Produção, prédio 07, sala 305, Centro de Tecnologia, Cidade Universitária, CEP 97.105-900, Santa Maria, RS, Brasil.

Telefones para contato: (055) 9614-5256

e-mail: loanataborda@yahoo.com.br

Nome completo: Lucinéia Carla Loeblein

Filiação institucional: Universidade Federal de Santa Maria - UFSM

Departamento: Programa de Pós Graduação em Engenharia de Produção - PPGEP

Função ou cargo ocupado: Mestranda

Endereço completo para correspondência (bairro, cidade, estado, país e CEP):

Universidade Federal de Santa Maria, Programa de Pós-Graduação em Engenharia de Produção, prédio 07, sala 305, Centro de Tecnologia, Cidade Universitária, CEP 97.105-900, Santa Maria, RS, Brasil.

Telefones para contato: (055) 9939-8785

e-mail: lucineiacarla@yahoo.com.br 
Nome completo: Andreas Dittmar Weise

Filiação institucional: Universidade Federal de Santa Maria - UFSM

Departamento: Programa de Pós Graduação em Engenharia de Produção - PPGEP

Função ou cargo ocupado: Professor

Endereço completo para correspondência (bairro, cidade, estado, país e CEP):

Universidade Federal de Santa Maria, Programa de Pós-Graduação em Engenharia de Produção, prédio 07, sala 305, Centro de Tecnologia, Cidade Universitária, CEP 97.105-900, Santa Maria, RS, Brasil.

Telefones para contato: (055) 3220-8619

e-mail: andreas.weise@ufsm.br

Nome completo: Sérgio Luiz Jahn

Filiação institucional: Universidade Federal de Santa Maria - UFSM

Departamento: Programa de Pós Graduação em Engenharia de Produção - PPGEP

Função ou cargo ocupado: Professor

Endereço completo para correspondência (bairro, cidade, estado, país e CEP):

Universidade Federal de Santa Maria, Programa de Pós-Graduação em Engenharia de Produção, prédio 07, sala 305, Centro de Tecnologia, Cidade Universitária, CEP 97.105-900, Santa Maria, RS, Brasil.

Telefones para contato: (055) 3220-8619

e-mail: jahn@smail.ufsm.br

Submetido em: 03/01/2014

Aceito em: 17/12/2014 